\begin{tabular}{llll}
\hline \multirow{2}{*}{$\begin{array}{l}\text { Kyoko Yagyu', } \\
\text { Tomoyo Morita', }\end{array}$} & 'Depart. Of Respiratory & Kyoko Yagyu: Department of & QF \\
Munetake Takata', & Medicine, Yodogawa & Respiratory Medicine, Yodogawa & \\
Yae Yoshida', & Christian Hospital & Christian Hospital, 2-9-26, Awaji & \\
Daijiro Nabeya', & 'Depart. Of Pathology, & Higashi-Yodogawa, Osaka, \\
Takao Kamimori', & Osaka City University & 533-O032 Japan \\
Mayumi Inaba2, & Graduate School Of & \\
Hiroshi Fujiwara' & Medicine, Osaka, Japan &
\end{tabular}

\title{
Bilateral diffuse micronodular changes of radiographic presentation in a 42 -year-old woman
}

\section{Case report}

A 42-year-old woman was found to have abnormal shadow on a chest radiograph obtained during a periodic health examination. She had a history of chronic nonproductive cough on effort for several months. The patient was admitted for investigation. Her past medical history was unremarkable and there were no allergies or occupational exposure. She rarely smoked and consumed little alcohol. During her childhood years, her father had been on chronic treatment for pulmonary tuberculosis.

The patient looked well with a blood pressure of $120 / 64 \mathrm{mmHg}$, heart rate of 64 beats $\cdot \mathrm{min}^{-1}$, regular respiratory rate of 14 breaths $\cdot \mathrm{min}^{-1}$ and a temperature of $36.8^{\circ} \mathrm{C}$. Examination of abdomen, nervous systems and cardiovascular and respiratory system were within normal limits. Finger clubbing wasn't noted on either hand and lymph nodes were not palpable. Her chest radiography and high-resolution CT (HRCT) scans are shown in figure 1.

\section{Task 1}

How would you interpret the chest radiography and HRCT?

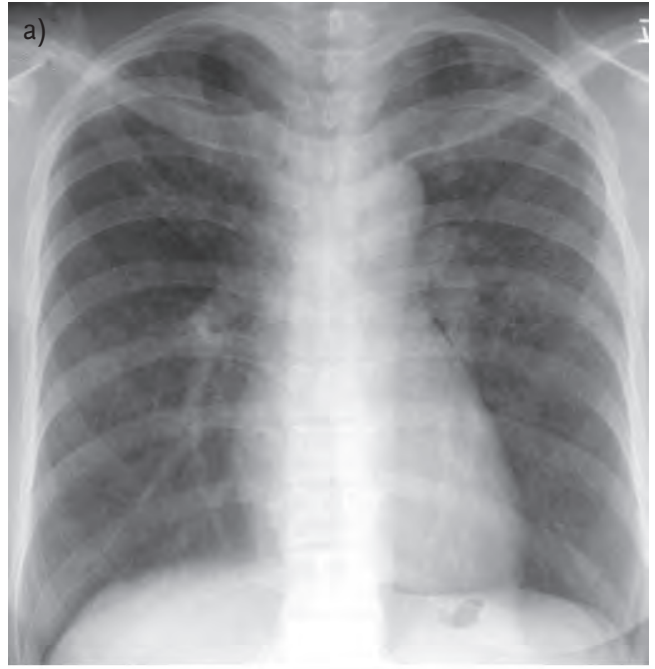

Statement of interest None declared.

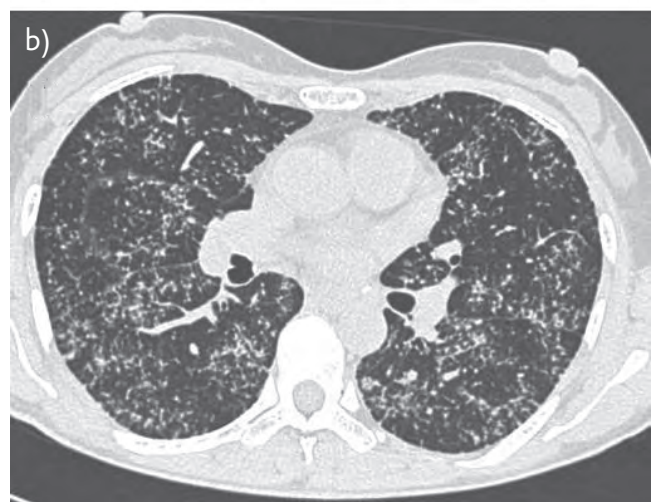

Figure 1

a) Plain radiograph shows micronodular lesions throughout both lungs, which are more prominent in the upper and middle zones. b) High-resolution CT scans of the chest at the level of the right upper lobar bronchus. 


\section{Answer 1}

The chest radiograph (fig. 1a) shows extensive diffuse shadowing in the upper and middle zones predominately and the HRCT (fig. 1b) revealed extensive diffuse lesions in the upper and middle lobes without cavitation, effusion, infiltration or suspicious scattering resource. There were extensive well-demarcated centriacinar nodules and peripheral branching linear structures that formed small $\mathrm{Y}$ - and $\mathrm{V}$ shaped lesions. These abnormalities were not present within 5-10 $\mathrm{mm}$ of the pleura.

Serological studies for HIV, chlamydia and mycoplasma were negative, as were antinuclear antibody, angiotensin-converting enzyme and tumour makers.

The exception was a slightly elevated Creactive protein level $\left(0.76 \mathrm{mg} \cdot \mathrm{dL}^{-1}\right)$. Haematology tests revealed a white blood cell count of 7,600 cells $\cdot \mathrm{mm}^{-3}$, haemoglobin of $13.4 \mathrm{~g} \cdot \mathrm{dL}^{-1}$ and platelet count of 264,000 cells $\cdot \mathrm{mm}^{-3}$. The tuberculin skin test was negative. Bacteriological cultures of sputum and gastric aspirate for acidfast bacillus were negative.
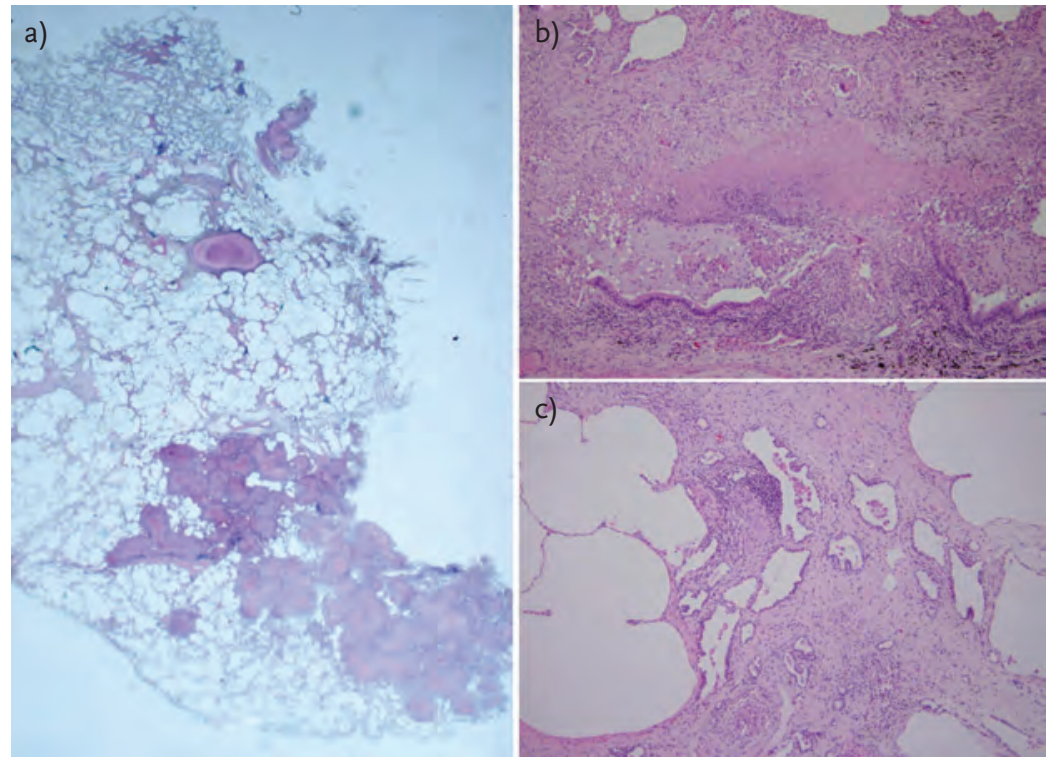

\section{Figure 2}

Histological examinations of open lung biopsy specimens from the upper and lower lobes. a) In a whole-mount section, necrotising granulomas are relatively small, rounded and well defined, but sometimes fuse to form large nodules (arrow). Haematoxylin and eosin staining $\times 10$; Scale bar: $10 \mathrm{~mm}$. b) Epithelioid granulomas with caseating necrosis involve the respiratory bronchioles and spread into the surrounding alveoli. Haematoxylin and eosin staining $\times 40$; scale bar: $100 \mu \mathrm{m}$. c) Respiratory bronchiole shows stenosis due to proliferation of epithelioid granulomas. Healing lesions are replaced by fibrous tissue. There is airspace enlargement in the adjacent areas. Haematoxylin and eosin staining $\times 40$; scale bar: $100 \mu \mathrm{m}$.
Arterial blood gas analysis while breathing room air showed hypoxaemia. Lung function tests revealed a normal flow rate and a slight decrease in diffusion capacity for carbon monoxide to $40.6 \%$ of the predicted value.

Bacteriological and cytological examination of washings and lung specimens obtained by transbronchial biopsy did not provide a specific diagnosis. Open lung biopsy was performed, targeting the left upper and lower lobes (fig. 2).

\section{Task 2}

How would you interpret the pathology? 


\section{Answer 2}

Pathological examination revealed epithelioid granulomas with caseating necrosis.

The necrotising granulomas were relatively small, round and well demarcated, but sometimes fused to create larger nodules. These lesions invaded the alveoli around the respiratory bronchioles, suggesting the spread of infection via the airways. Endobronchial growth of the granulomas was also seen. In the pulmonary acini, some of the granulomas had progressed to fibrosis and healed completely (fig. 2).

\section{Task 3 \\ What is your diagnosis?}

\section{Answer 3}

The diagnosis of pulmonary tuberculosis was made.

Acid-fast bacilli were detected by ZiehlNeelsen staining in this pathological examination. Culture of the biopsy material grew Mycobacterium tuberculosis without any resistance to antituberculous drugs.

Immediately, the patient started on therapy with isoniazid, rifampicin, pyrazinamide and etambutol. Follow-up CT and chest radiography showed improvement after 6 months of antituberculous chemotherapy. Her symptoms and hypoxaemia also resolved.

\section{Discussion}

Classically, reactivation of pulmonary tuberculosis in adults affects the apical or posterior segments of the upper lobe, or else the superior segment of the lower lobe [1]. However, a variety of radiographic findings have become more frequent in recent years. This phenomenon, thought to be related to the increased use of steroid therapy, immunosuppressive therapy and anticancer drugs, as well as the growth of the elderly population. According to HADLOCK et al. [2], who reported unusual radiographic finding of pulmonary tuberculosis in adults, the incidence of a miliary pattern in 270 patients was $0.4 \%$ [2]. The incidence of similar cases among 100 patients was $3.0 \%$ in a series by MiLLER and MACGREGOR [3].

A diffuse micronodular pattern on chest radiographs is not only seen in pulmonary tuberculosis, but also in diffuse panbronchiolitis, infectious bronchiolitis, hypersensitivity pneumonitis, pneumoconiosis, sarcoidosis, primary lymphoma, alveolar cell lung cancer and amyloidosis. Several authors have investigated diffuse micronodular changes on radiographs to assess the correlations with HRCT and pathological findings and it has been shown that a micronodular pattern of pulmonary tuberculosis comprises miliary tuberculosis combined with endobronchial spread of infection $[4,5]$. On HRCT, miliary tuberculosis is seen as tiny nodules randomly distributed throughout the lung parenchyma. These nodules are uniform and are distributed without any relation to the airways. In the present case with disseminated endobronchial pulmonary tuberculosis, HRCT revealed well-demarcated centriacinar opacities and peripheral branching linear structures $(2-5 \mathrm{~mm}$ in diameter) in the upper and middle lobes. These lesions were small and irregular ( $Y$ - and $\mathrm{V}$-shaped) with high attenuation, and showed a dense segmental distribution in the upper and middle lobes, while being sparse in the lower lobe (fig. 1b). According to Coluins et al. [6], bronchioles filled by tuberculous inflammatory exudates or granulation tissue are seen as centrilobular and linear branching opacities, which were described as acino-nodular lesions. This pattern is analogous to the "tree-in-bud" appearance of the airways in patients with bronchial impaction. However, the lesions seem to involve much more distal airways than those creating the tree-in-bud appearance. Pathological examination revealed compact nodules of caseating necrosis that filled the terminal bronchioles. These lesions corresponded to the centriacinar and linear branching changes 
on CT scans. In whole-mount sections, fibrotic alveoli were scattered among normal lung tissue. Each focus of fibrotic change was associated with localised emphysema in the adjacent lung tissue that might lead to bronchiolar distortion or emphysema in the future (fig. 2). Generally, the lesions of pulmonary tuberculosis have various stages, including the proliferative, sclerosing, and fibrosing phases. However, the lesions in this particular case maintained the mild and uniform stage of progression. Furthermore, these lesions preferentially involved the peripheral airways or the acini.

SCHMIDT [7] originally reported this type of bronchogenic pulmonary tuberculosis as "die acinös-nodöse Lungentuberkulose". Additonally, chronic disseminated acinar pulmonary tuberculosis has been elucidated as Oka's classification of pulmonary tuberculosis type IIB in Japan [8], but it may be considered as an extensive tree-in-bud appearance.

It seems that the progression of tuberculosis is more complex than that of other bacterial pulmonary infections. An uncommon mode of progression like this case presumably arises from the interplay between bacterial virulence factors and the cell-mediated immunity of the host. Recently, dendritic cells in the peripheral airways have been recognised as professional antigen-presenting cells rather than alveolar macrophages in association with the primary immune response [9]. Cytokines secreted by dendritic cells and macrophages, as well as interferon- $\gamma$ produced by natural killer Tcells and $\gamma \delta$ T-cells in the early period of infection, strongly induce macrophage activation and the development of antigen-specific interferon- $\gamma$-producing CD4+ T-cells [10]. In this process, dendritic cells play an important role as antigen-presenting cells.

In the present case, we were unable to diagnose pulmonary tuberculosis initially. It seems that the number of bacilli in the sputum was relatively small. Considering the other diffuse micronodular lung diseases that produce similar acino-nodular lesions as those seen in this case of pulmonary tuberculosis, we should have listed the differential diagnosis more carefully because interferon- $\gamma$ released assay by T-cell (QuantiFERON TB-2G; Cellestis, Carnegie, Australia) was unavailable at that time.

In conclusion, this case illustrates the radiological and pathological correlates of diffuse micronodular pulmonary tuberculosis. HRCT demonstrated well-defined centriacinar lesions and extensive peripheral branching linear structures. Pathological examination revealed compact epithelioid granulomas with caseating necrosis extending from the respiratory bronchioles to the surrounding alveoli. It is important to diagnose carefully such cases and not confuse tuberculosis with other types of diffuse lung disease.

\section{Acknowledgements}

The authors would like to thank A. Hebisawa (Division of Clinical Laboratory, Tokyo Hospital, Japan) for advice about the pathological findings.

\section{References}

1. Farman DP, Speir WA. Initial roentgenographic manifestations of bacteriologically proven Mycobacterium tuberculosis: typical or atypical? Chest 1986; 89: 75-77.

2. Hadlock FP, Park SK, Awe RJ, et al. Unusual radiographic findings in adult pulmonary tuberculosis. Am J Roentgenol 1980; 134: 1015-1018.

3. Miller WT, Macgregor RR. Tuberculosis: frequency of unusual radiographic findings. Am J Roentgenol 1978; 130: $867-875$.

4. Rossi SE, Franquet T, Volpacchio M, et al. Tree-inbud pattern at thin-section CT of the lungs: radiologic-pathologic overview. RadioGraphics 2005; 25: 789-801.

5. Lee KS, Kim TS, Ham J, et al. Diffuse micronodular lung Disease; HRCT and pathologic findings. J Comput Assist Tomogr 1999; 23: 99-106.
6. Collins J, Blankenbaker D, Stern EJ. CT patterns of bronchiolar disease: What is "tree-in-bud"? Am J Roentgenol 1998; 171: 365-370.

7. Schmidt PG. [Differentialdiagnose der Lungenkrankheiten mit besonderer Berücksichtingung der Tuberklose.]. Tuberkulose-Bibliothek 1936; 60: 44-47.

8. Tokuda $\mathrm{H}$. Pathogenesis of chronic disseminated acinar pulmonary tuberculosis: Oka's classification of pulmonary tuberculosis type IIB discussion through an analysis of two typical cases. Kekkaku 2007; 82: 507-513.

9. Wolf AJ, Linas B, Trevejo-Nuñez GJ, et al. Mycobacterium tuberculosis infects dendritic cells with high frequency and impairs their function in vivo. J Immnol 2007; 179: 2509-2519.

10. Kaufmann SHE. Protection against tuberculosis: cytokines, T cell, and macrophages. Ann Rheum Dis 2002; 61: ii54-ii58. 